\title{
1 PILOT STUDY
}

3 Preliminary investigation of the influence of long-term dietary isoflavone intake on

4 reproductive tract histology and sex steroid receptor expression in female domestic

5 cats (Felis catus)

\section{Summary}

7 Genistein and daidzein are isoflavones which are reported to influence the reproductive

8 system in a variety of mammalian species. This pilot study aimed to determine if dietary

9 isoflavones could potentially influence reproductive tract histology or morphology in

10 domestic cats, when consumed during the postnatal development period. Cats were

11 maintained on either treatment $(150 \mu \mathrm{g} / \mathrm{g}$ DM genistein and $150 \mu \mathrm{g} / \mathrm{g}$ DM daidzein, $\mathrm{n}=4)$

12 or control (isoflavone free, $n=8$ ) diets from weaning, up to 414 ( \pm 17.2 ) days post-

13 weaning. Reproductive tissues were collected during routine ovario-hysterectomy and

14 examined for histology and sex steroid receptor expression. Findings indicate that these

15 dietary isoflavones influenced the expression of oestrogen receptor $\alpha(\mathrm{ER} \alpha)$ and

16 oestrogen receptor $\beta$ (ER $\beta)$, and progesterone receptor in feline reproductive tissues. One

17 cat in the treatment group developed suppurative endometritis, but no evidence of

18 uterotrophic or histological changes were found in any other cats. The potential to alter

19 expression of hormone receptors in the reproductive tract of domestic cats exposed to

20 genistein and daidzein warrants further investigation.

21 Keywords: cat, daidzein, genistein, oestrogen, progesterone, reproduction

22 Date received: $10^{\text {th }}$ April 2013 
23 Date accepted: $1^{\text {st }}$ July 2013

\section{Introduction}

25 Dietary isoflavones are phenolic compounds found in soy and other legumes, which have

26 oestrogenic and anti-oestrogenic properties (Kurzer and Xu, 1997). A diverse array of

27 hormonal and non-hormonal effects have been observed in isoflavone-exposed rodents,

28 pigs and humans, including oestrogen receptor binding, and morphological and

29 histological changes (Barnes et al 2000; Ford et al 2006; McClain et al 2006).

30 Domestic cats ingest, absorb, and metabolise soy isoflavones present in commercial diets

31 (Bell et al., 2006; Cave et al., 2007). Some feline diets expose cats to isoflavone

32 concentrations potentially capable of eliciting physiological changes (i.e. $>2 \mathrm{mg} / \mathrm{kg}$ BW)

33 (Bell et al 2006). The isoflavones, genistein and daidzein, comprise the isoflavones

34 detected in the highest concentrations in commercially prepared cat food (Bell et al

35 2006). Thus, it is important to ascertain the reproductive consequences of this level of

36 genistein and daidzein exposure in this species. The present study was conducted to

37 determine the potential for genistein and daidzein to alter reproductive parameters in the

38 domestic cat, when provided at concentrations reflective of normal dietary exposure.

\section{Materials and Methods}

40 Eighteen female short-haired, domestic cats (Felis catus) were enrolled in the study and

41 assigned to either the control group $(n=9)$ or treatment group $(n=9)$ at weaning.

42 However, six cats were removed from the trial (two due to failure to consume the test diet

43 within the first week, and four due to unrelated medical conditions prior to planned tissue

44 collection). Cats were group-housed in multi-level pens, exposed to natural day/night 
45 cycles. At 10 weeks of age, the cats were removed from the queen's pens, and separated

46 into treatment (mean age $72 \pm 1.89 \mathrm{~d}$; BW $0.87 \pm 0.07 \mathrm{~kg}$ ) and control (mean age $71 \pm$

47 2.39d; BW $0.93 \pm 0.05 \mathrm{~kg}$ ) groups. Ethical approval was obtained from the Massey

48 University Animal Ethics Committee.

49 The basal diet for both groups was a moist feline diet, commercially-prepared and

50 formulated to meet the requirements for growth in the domestic cat (AAFCO 2009). This

51 diet was assayed to contain no detectable levels of isoflavones (Bell et al., 2006). The

52 purified (99.9\%) form of each isoflavone, genistein and daidzein (LC Laboratories, MA,

53 USA), was added to the basal diet to provide a calculated dose of $300 \mu \mathrm{g}$ total

54 isoflavone/g DM. Samples of the control and treatment diets were assayed for isoflavone

55 content at monthly intervals throughout the trial according to methodology described in

56 Bell et al. (2006). Cats were provided water ad libitum during the trial, and offered

57 enough food to provide each cat with appropriate energy intake for age (i.e. $217 \mathrm{kcal} / \mathrm{kg}$

$58 \mathrm{BW} / \mathrm{d}$ at eight weeks old, gradually reducing to $88 \mathrm{kcal} / \mathrm{kg} \mathrm{BW} / \mathrm{d}$ by 40 weeks; Legrand-

59 Defretin and Munday, 1993). Food was weighed before and after offering to each group

60 and daily refusals were used to calculate intake per pen, which was then used to estimate

61 intake per cat. Monthly assessments were made of individual food intake by separation of

62 each cat into individual metabolism cages for a 24 hour period, during which time food

63 was offered in quantities calculated to provide twice the cat's energy needs, and food

64 intake and urinary and faecal output were recorded.

65 Vaginal cytology confirmed that cats were in inter-oestrous at the time of reproductive

66 tract collection. Tissue collection was performed under halothane anaesthesia, according

67 to standard veterinary procedures, at a mean age of 481 days (SEM 21.4) in the control 
68 group, and 429 (SEM 62.9) in the treatment group (differences due to older cats in the

69 treatment group being removed from the study). Surgical procedures were performed on

70 all cats in both groups at the same point in time (across two days) and by the same

71 surgeon. Reproductive tracts (including ovaries, uterine horns and cervix) were weighed

72 and ovarian surfaces examined for the presence of visible follicles, corpora lutea, and

73 corpora haemorrhagica. Reproductive organs were fixed in 10\% buffered formalin

74 before being processed for histology and immunohistochemical (IHC) analysis.

75 Haematoxylin and eosin-stained slides were examined by a veterinary histopathologist

76 (author; W.R.; blinded to treatment) and screened for abnormalities according to standard

77 veterinary procedures.

78 An IHC assay for assessment of ER $\alpha$, ER $\beta$ and progesterone receptor (PR) was

79 developed from the method of Martin de las Mulas et al (2000). The ER $\alpha$, ER $\beta$ and PR

80 were identified using monoclonal mouse antibodies, IgG1 (NCL-ER-6F11, NCL-ER $\beta$;

81 Vision Biosystems, Victoria, Australia) and PR4-12 (Merck, Palmerston North, New

82 Zealand), respectively) validated for use in feline tissue.

83 Histological sections were de-paraffinised and rehydrated by sequential immersion in

84 xylene and graded alcohol baths. Sections were microwave-heated (high power, 750W

85 microwave oven for $7 \mathrm{~min}$ ) in citrate buffer ( $10 \mathrm{mM}$ citric acid, $\mathrm{pH}$ 6.0). Sections were

86 washed in phosphate-buffer solution (PBS) before non-specific binding sites in the tissue

87 were blocked by the application of $100 \mu \mathrm{l}$ of $10 \%$ Bovine Serum Albumin (BSA) (Roche

88 Diagnostics, Mannheim, Germany) in ovine serum and PBS. Sections were incubated at

89 room temperature in a moist chamber for 45 min before BSA/serum was removed and the

90 primary antibody applied (ER $\alpha, E R \beta$ or $P R$ ) at dilutions confirmed in preliminary 
91 experiments to yield optimal results (1: 50 for ER $\alpha$ and ER $\beta, 1: 30$ for PR). Sections

92 were incubated overnight at room temperature before the primary antibody was removed

93 and the tissues incubated with biotinylated goat, anti-mouse IgG (Invitrogen Life

94 Technologies, Auckland, NZ) for 1 hour before a fluorescent marker was added

95 (Streptavidin, Alexa Fluro 546 conjugate, Molecular Probes Inc., OR, USA, diluted 1:

96 20). Following a final incubation of 1 hour, slides were washed in cold tap water and

97 counter-stained with haematoxylin.

98 Positive control tissues (control cat uterine tissue and human breast cancer tissue) were

99 incubated with each of the three primary antibodies and processed according to the same

100 methodology as test tissues. Tissues were examined by one investigator (author; KW-T)

101 using $40 \mathrm{x}$ magnification with epi-fluorescence illumination (488 nm), and 100 individual

102 cells were analysed for fluorescence-staining intensity and extent using Java-based image

103 processing software (ImageJ, version 1.38; Rasband 2007). The level of light staining

104 intensity detected in negative control tissue was the threshold of background

105 luminescence used to define positive staining in test sections.

106 For the statistical analysis, data that were not normally distributed were tested for

107 differences between groups using the Mann-Whitney test. For proportional data the

108 Fisher exact test was used to compare differences. All other parameters were tested for

109 between-group differences using ANOVA. All statistical procedures were carried out

110 with Minitab software (version 15, Minitab Inc., PA, USA) with confidence limits set at

$11195 \%$.

\section{Results and Discussion}


113 Four cats consumed the treatment diet and eight cats consumed the control diet for the

114 duration of the study. By the end of the trial, treatment cats were consuming an average

115 of $4.88-5.19 \mathrm{mg}$ total isoflavones/kg BW/d, providing approximately equal doses of

$1162.44-2.56 \mathrm{mg} / \mathrm{kg} \mathrm{BW/d}$ of genistein and daidzein.

117 No significant differences were observed between groups in reproductive tract wet weight

118 (Table 1), indicating no gross morphological changes following isoflavone exposure.

\section{Table 1 here}

120 This is in contrast with previous studies in other species in which uterine hypertrophy has

121 been reported following exposure to isoflavones in rats (Santell et al. 1997; McClain et al

122 2005) and dogs (McClain et al. 2006). With the exception of one cat diagnosed with

123 subacute suppurative endometritis (discussed below), no histological abnormalities were

124 detected in ovarian or uterine tissue from any other cat, and no histological differences

125 were detected between treatment and control groups. The number of corpora lutea, or

126 primary, secondary, tertiary, mature or atretic follicles in cat ovaries did not differ

127 between groups. It is possible that the lower dose provided (reflecting the higher end of

128 the typical dietary intake range calculated by Bell et al., 2006), and the use of an oral

129 administration route, which results in low bioavailability (Cave et al., 2007), may explain

130 the differences observed here compared to previous studies, whereby only dogs exposed

131 to $500 \mathrm{mg} / \mathrm{kg} \mathrm{BW}$ (compared to $50 \mathrm{mg} / \mathrm{kg} \mathrm{BW}$ and $150 \mathrm{mg} / \mathrm{kg}$ BW groups) exhibited

132 uterine hypertrophy (McClain et al., 2006). Alternatively, the duration of administration

133 in this present study exceeds previous studies, and acute responses may have been

134 missed. This is supported by the finding that uterine hypertrophy was detected in dogs 
135 following 13 weeks of exposure to a high genistein dose (500 mg/kg BW) but not

136 following 52 weeks exposure (McClain et al., 2006)

137 However, differences detected in receptor staining between groups indicate a role for

138 dietary isoflavones in modulating reproductive physiology in domestic cats. Expression

139 of $E R \alpha$ and $E R \beta$ receptors was greater in treated cats compared to control cats $(P<0.05)$,

140 with the exception of ER $\alpha$ in the uterine basal endometrium and myometrium, where

141 expression was greater in control tissues $(P<0.05$; Table 2$)$. No difference was detected

142 between groups in ER $\beta$ or PR expression in the myometrium. The up-regulation of

143 cellular expression of ER $\alpha$ and $E R \beta$ in the ovarian cortex, medulla and uterine

144 endometrium observed in response to isoflavone treatment here, has been reported in

145 other species (Jefferson et al 2002; Chrzan and Bradford 2007). Genistein and daidzein

146 are capable of binding to both ERs, with preferential binding and transactivation shown

147 for ER $\beta$ (reviewed in Rietjens et al 2013). These isoflavones act as nuclear receptor

148 ligands to enhance interactions between oestrogen-related receptors and proline-rich

149 nuclear receptor coactivator (PNRC) (reviewed in Ricketts et al., 2005).

\section{Table 2 here}

151 Conversely, proportional expression of the PR was typically down-regulated in

152 isoflavone-treated cat uterine and ovarian sections. Progesterone receptor expression was

153 lower in treatment cats compared to control cats in ovarian cortex and uterine apical

154 endometrium $(P<0.05)$, while no difference was detectable in the ovarian medulla and

155 myometrium; in the uterine basal endometrium PR expression was greater in treatment

156 cats $(P<0.05)$. These sex steroid receptors are important mediators in the control of

157 oestrogen- and progesterone-induced effects during oestrous cyclicity and pregnancy, 
158 such that modifications at the receptor level may be reflected in aberrant physiological

159 responses or fertility.

160 One cat in the treatment group was diagnosed with subacute suppurative endometritis at

161267 days of age. This cat's tissue morphological data was excluded due to its diseased

162 state. The development of suppurative endometritis in an isoflavone-treated cat was an

163 unexpected finding. This condition is not common in cats, and is generally only reported

164 in cats older than eight years of age (Agudelo 2005), but further research is required to

165 determine the role that isoflavones may have played in the onset of the condition in the

166 cat reported here.

\section{Conclusions}

168 Preliminary findings suggest that the isoflavones, genistein and daidzein may exert

169 modulatory effects on the expression of sex steroid receptors in feline uterine tissue.

170 Given the limited sample size our findings should be considered as preliminary and

171 interpreted with caution. Future investigation should include life-time evaluation of

172 feline fertility and fecundity, with increased sample sizes.

\section{References}

174 AAFCO. (2009) Official publication of the Association of American Food Control

175 Officials Inc. Oxford, Indiana, USA.

176 BARNES, S., KIM, H., DARLEY-USMAR, V., PATEL, R., XU, J., BOERSMA, B.,

177 and LUO, M. (2000) Beyond ER $\alpha$ and ER $\beta$ : estrogen receptor binding is only part of the

178 isoflavone story. Journal of Nutrition, 130: 656S - 657S. 
180 content of commercially available feline diets in New Zealand. New Zealand Veterinary

181 Journal, 54: 103-108.

182 CAVE, N.J., BACKUS, R.C., MARKS, S.L., and KLASING, K.C. (2007) The

183 bioavailability and disposition kinetics of genistein in cats. Journal of Veterinary

184 Pharmacology and Therapeutics, 30:327-335.

185 CHRZAN, B.G., and BRADFORD, P.G. (2007) Phytoestrogens activate oestrogen

186 receptor $\beta 1$ and oestrogenic response in human breast and bone cancer cell lines.

187 Molecular Nutritional Food Research, 51:171 - 177.

188 FORD, J.A. JR., CLARK, S.G., WALTERS, E.M., WHEELER, M.B., and 189 HURLEY, W.L. (2006) Estrogenic effects of genistein on reproductive tissues of 190 ovariectomized gilts. Journal of Animal Science, 84834 - 842.

191 JEFFERSON, W.N., COUSE, J.F., PADILLA-BANKS, E., KORACH, K.S., and

192 NEWBOLD, R.R. (2002) Neonatal exposure to genistein induces oestrogen receptor

193 (ER) $\alpha$ expression and multioocyte follicles in the maturing mouse ovary: Evidence for

194 ERß-mediated and nonoestrogenic actions. Biology of Reproduction, 67:1285-1296.

195 KURZER, M.S. and XU, X. (1997) Dietary phytoestrogens. Annual Reviews in

196 Nutrition 17: 353-381.

197 LEGRAND-DEFRETIN, V., and MUNDAY, H.S. (1993) Feeding dogs and cats for

198 life, in BURGER, I. (Ed.) The Waltham Book of Companion Animal Nutrition, pp. 57068

199 (Pergamon Press, Oxford, UK).

200 MARTIN DE LA MULAS, J., VAN NIEL, M., MILLÁN, Y., BLANKENSTEIN,

201 M.A., VAN MIL, F., and MISDORP, W. (2000) Immunohistochemical analysis of 
202 oestrogen receptors in feline mammary gland benign and malignant lesions: comparison

203 with biochemical assays. Domestic Animal Endocrinology, 18:111 - 125.

204 McCLAIN, R.M., WOLZ, E., DAVIDOVICH, A., PFANNKUCH, F., and BAUSCH,

205 J. (2005) Subchronic and chronic safety studies with genistein in dogs. Food and

206 Chemical Toxicology, 43: $1461-1482$.

207 McCLAIN, R.M., WOLZ, E., DAVIDOVICH, A., PFANNKUCH, F., EDWARDS,

208 J.A., and BAUSCH, J. (2006) Acute, subchronic and chronic safety studies with

209 genistein in rats. Food and Chemical Toxicology, 44: 56 - 80.

210 RICKETTS, M-L., MOORE, D.D., BANZ, W.J., MEZEI, O., SHAY, N.F. (2005).

211 Molecular mechanisms of action of the soy isoflavones includes activation of

212 promiscuous nuclear receptors. A review. Journal of Nutritional Biochemistry, 16: 321 213330.

214 
Table 1 Wet weights (as grams or \% body weight) of reproductive tracts obtained from domestic cats following chronic isoflavone exposure (treatment group) or control animals $^{1,2}$.

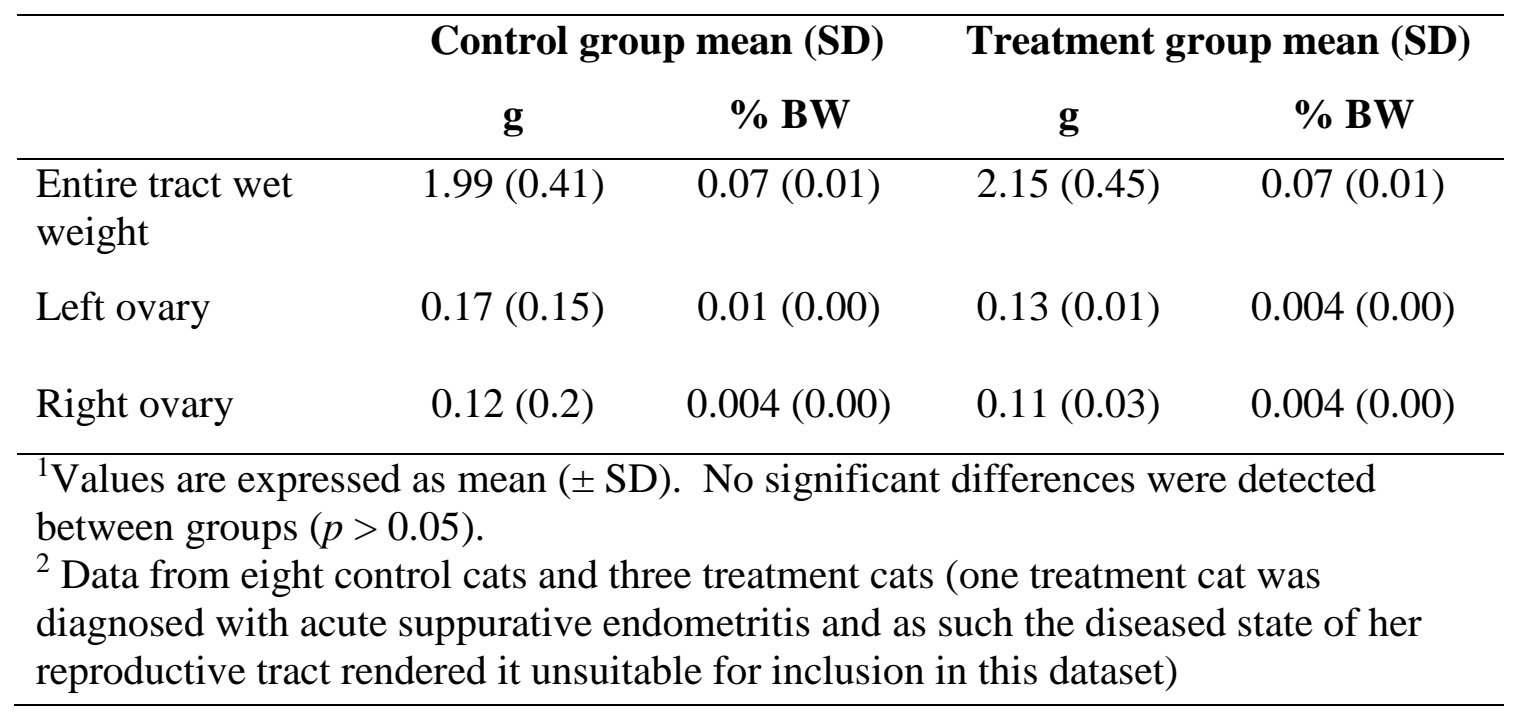


Table 2 The proportion of cells staining positive for ER $\alpha, E R \beta$, or PR in the reproductive tract of cats exposed to dietary genistein and daidzein, compared to control cats ${ }^{1}$.

\begin{tabular}{|c|c|c|c|c|c|c|}
\hline & \multicolumn{2}{|c|}{ ERa } & \multicolumn{2}{|c|}{ ERß } & \multicolumn{2}{|c|}{ PR } \\
\hline & Control & Treatment & Control & Treatment & Control & Treatment \\
\hline Ovarian cortex & $0.58(0.44)^{\mathrm{a}}$ & $0.79(0.18)^{b}$ & $0.57(0.46)^{\mathrm{a}}$ & $0.83(0.26)^{b}$ & $0.75(0.49)^{\mathrm{b}}$ & $0.66(0.31)^{\mathrm{a}}$ \\
\hline Ovarian medulla & $0.52(0.46)^{\mathrm{a}}$ & $0.94(0.05)^{\mathrm{b}}$ & $0.79(0.21)^{\mathrm{a}}$ & $0.93(0.13)^{b}$ & $0.72(0.29)^{\mathrm{a}}$ & $0.76(0.42)^{\mathrm{a}}$ \\
\hline Uterine basal endometrium & $0.91(0.22)^{b}$ & $0.84(0.19)^{\mathrm{a}}$ & $0.79(0.33)^{\mathrm{a}}$ & $0.95(0.11)^{b}$ & $0.76(0.20)^{\mathrm{a}}$ & $0.88(0.22)^{\mathrm{b}}$ \\
\hline Myometrium & $0.60(0.33)^{b}$ & $0.32(0.17)^{\mathrm{a}}$ & $0.53(0.35)^{\mathrm{a}}$ & $0.59(0.22)^{\mathrm{a}}$ & $0.64(0.31)^{\mathrm{a}}$ & $0.63(0.12)^{\mathrm{a}}$ \\
\hline
\end{tabular}

